Additional services for Journal of Fluid Mechanics:

Email alerts: $\underline{\text { Click here }}$

Subscriptions: Click here

Commercial reprints: $\underline{\text { Click here }}$

Terms of use : $\underline{\text { Click here }}$

Dynamics of Meteorology and Climate. By R. S. SCORER. Wiley-Praxis Series in Atmospheric Physics, 1997. 608 pp. ISBN 047196816 1. £29.95.

\title{
I. Eames
}

Journal of Fluid Mechanics / Volume 390 / July 1999, pp 374 - 377

DOI: 10.1017/S0022112099215261, Published online: 08 September 2000

Link to this article: http://journals.cambridge.org/abstract_S0022112099215261

How to cite this article:

I. Eames (1999). Journal of Fluid Mechanics, 390, pp 374-377 doi:10.1017/S0022112099215261

Request Permissions : $\underline{\text { Click here }}$ 


\section{BOOK REVIEWS}

Dynamics of Meteorology and Climate. By R. S. SCORER. Wiley-Praxis Series in Atmospheric Physics, 1997. 608 pp. ISBN 047196816 1. £29.95.

This book, published in an Atmospheric Physics series aimed at graduate students and researchers in the area of meteorology, has developed over the last forty years. It was first published as Natural Aerodynamics (1958); the material was elaborated to give Environmental Aerodynamics (1978) (reviewed by J. S. Turner in vol. 90 (1979), p. 369 ), and expanded to the current volume (608 pages). Much of the material remains highly original, and gives revealing accounts of many fundamental aspects of fluid mechanics, discussed with relevance to meteorological observations. The author has communicated his enthusiam for fluid mechanics and has illustrated many points visually using experimental observations and satellite images. This an excellent book and is required reading for all fluid mechanicians especially in areas as diverse as aerodynamics, meteorology, environmental and geophysical fluid mechanics.

The book consists of three parts, totalling 20 chapters. Part 1 deals with fundamental aspects of fluid mechanics, waves and instability (274 pages in 8 chapters), Part 2 deals with turbulence, jet/plume theory, clouds and dispersion ( 283 pages in 7 chapters) and Part 3, where most of the new material appears, deals with forecasting and climate change (93 pages in 5 chapters). In Part 1, the author gives a clear and concise description of the fundamentals of fluid mechanics, including in Chapter 3 the clearest and only account, as far as I am aware, of 'secondary flow' analysis in a graduate textbook. This powerful method is still being applied to new practical problems. A wide range of intriguing photographs are provided to illustrate the lee wave generation, wave propagation in stratified fluids, and flow instabilites. Part 2 contains treatments of jet and plume dynamics in inhomogeneous flows, which is especially topical given the resurgence of interest in enviromental and geophysical flows. A number of diverse subjects, such as locust swarms in deserts intertwined with biblical quotes, provides stimulating reading. Part 3 contains a very general discussion of forecasting and long-term climate change.

Some critical comments must be made. The material in Part 3 is quite wide-ranging and unfocused in parts, with the author jumping between many different subjects on a single page. There appears to have been little attempt to integrate Part 3 , which is nontechnical, with the remainder of the book. Moreover, the new title, Dynamics of Meteorology and Climate, does not adequately describe the contents of this book and refers principally to Part 3. Far too many typographical errors appear to have been created by re-typesetting Parts 1 and 2, for example there are two errors in the second equation on page 44, although the meaning (for an experienced reader) remains clear. Furthermore, the list of recommended additional reading refers primarily to climate change and does not include more recent references to supplementary material for Parts 1 and 2 (the lack of up-to-date references in the previous version was criticized by Turner).

Despite these criticisms, this is a inspiring book based on Professor Scorer's lifetime experience in the area of meteorology. This book is strongly recommended for undergraduates, graduates and researchers in the general area fluid mechanics, and is expected to have a wide appeal to chemical/mechanical engineers, students of environmental and geophysical fluid mechanics and meteorologists. 